University of Nebraska - Lincoln

DigitalCommons@University of Nebraska - Lincoln

College of Law, Faculty Publications

Law, College of

2011

\title{
Teaching Controversial Topics
}

Jennifer S. Hendricks

University of Tennessee

Beth Burkstrand-Reid

University of Nebraska-Lincoln

June Carbone

University of Missouri - Kansas City

Follow this and additional works at: https://digitalcommons.unl.edu/lawfacpub

Part of the Legal Studies Commons

Hendricks, Jennifer S.; Burkstrand-Reid, Beth; and Carbone, June, "Teaching Controversial Topics" (2011). College of Law, Faculty Publications. 94.

https://digitalcommons.unl.edu/lawfacpub/94

This Article is brought to you for free and open access by the Law, College of at DigitalCommons@University of Nebraska - Lincoln. It has been accepted for inclusion in College of Law, Faculty Publications by an authorized administrator of DigitalCommons@University of Nebraska - Lincoln. 


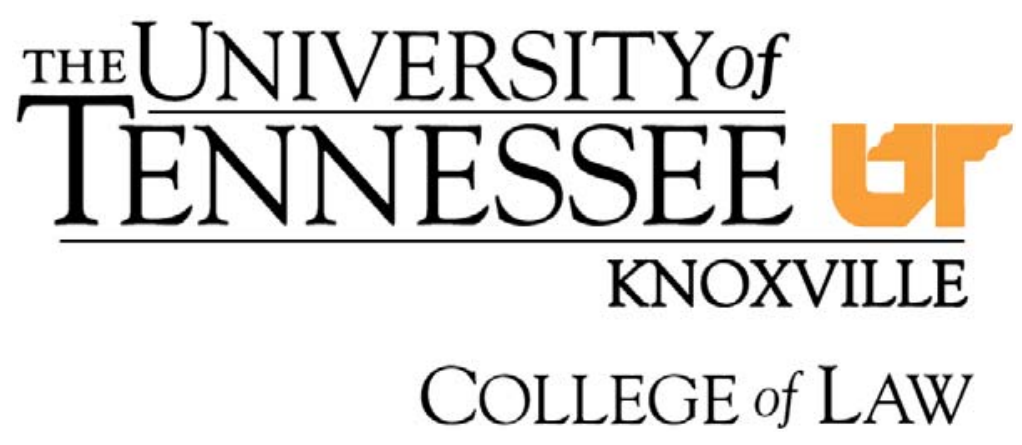

Legal Studies Research Paper Series

Research Paper \#145

April 2011

\title{
Teaching Controversial Topics
}

\author{
Jennifer S. Hendricks \\ \& \\ Beth Burkstrand-Reid \\ \& \\ June Carbone
}




\title{
TEAching Controverial TOPICS
}

\author{
Jennifer S. Hendricks ${ }^{1}$, Beth Burkstrand-Reid ${ }^{2} \&$ June Carbone $^{3}$
}

\section{FAM. CT. REV. (forthcoming 2011)}

At the 2009 Future of Family Law Education conference at the William Mitchell School of Law, the authors participated in a panel discussing strategies for teaching controversial topics, which focused on teaching reproductive rights and related gender issues. This essay collects some of the strategies discussed at the conference. First we address what constitutes a "controversial" legal topic, outlining the several different ways in which a topic might be or become controversial within the context of a particular class. Next, we discuss the importance of laying the groundwork, throughout the semester, for the anticipated — and unanticipateddiscussions surrounding controversial topics and techniques for laying that groundwork. Finally, we outline specific classroom techniques and resources to aid professors at the time controversial topics in the classroom are confronted.

\section{What Is a Controversial Topic?}

Family law may be controversial in a variety of ways and for a variety of reasons. Most controversial topics fall into one or more of the following categories: politicized issues, issues easily personalized, and issues easily magnified by extremism or lack of diversity. Many of the

\footnotetext{
${ }^{1}$ Associate Professor of Law, University of Tennessee College of Law

${ }^{2}$ Assistant Professor of Law, University of Nebraska College of Law

${ }^{3}$ Edward A. Smith/Missouri Chair of Law, the Constitution and Society Professor, University of Missouri- Kansas City School of Law
} 
most controversial issues, such as reproductive rights or same-sex marriage, for example, may fall into all of these categories. When a legal topic falls into one or more of these categories, controversy should be anticipated and planned for.

The most easily recognizable controversial topics are those that are heavily politicized. Most professors planning a general course in family law will expect reproductive rights, especially abortion, to be controversial. Because abortion is frequently discussed in politics and religion, the grooves of the standard arguments are already worn into students' minds. Students easily fall back onto talking points and fixed positions rather than remaining open to intellectual exploration of the legal regime surrounding this topic. Politicized topics and rigidity in thinking often go hand-in-hand. This complicates efforts to use controversial topics such as abortion, for example, as a vehicle for teaching in an intersectional manner, such as by incorporating feminist theoretical analyses of legal regimes into case-method teaching. Adherence to political scripts complicates the intellectual exploration of rich topics including abortion, religious freedom, and sexuality.

Controversy also tends to arise when topics can be personalized by students. Topics are personalized in many ways, but two scenarios are the most common: (1) first-personalization and (2) secondary personalization. First-person personalization is exactly how it sounds: students who, for example, have been themselves been raped, had abortions, or gone through divorce, whose thoughts may be difficult to express in terms of the standard talking points and who may experience the class discussion as passing judgment on them. Secondary personalization occurs when even people who lack that personal experience tend to personalize the issue. For example, women and men may, in different ways, both tend to personalize issues of rape law even if they 
have not personally experienced the crime. If students have strong emotional feelings, they may be uncomfortable talking about it in a law school environment — or they may want to talk about it a great deal but not have much interest in listening to peers who express contrary views. Such strong feelings may result in the marginalization of significant portions of a class and may even lead students to direct anger at professors for "failing" to personally defend students or student viewpoints.

A topic may also become controversial or personal not because the issue inherently has resonance for particular students but because of a lack of diversity in the classroom. That lack of diversity may or may not be visible to the professor. For example, the professor will probably be aware of a lack of racial diversity and the risk of putting minority students in the "spokesperson" role on family law topics such as inter-racial adoption and the Indian Child Welfare Act. On the other hand, the professor likely does not know students' sexual orientation and may not pick up immediately on personal aspects of the class discussion that are apparent to students. There may also be a lack of diversity in political opinions, or perhaps you or a student wants to introduce a controversial position. What may not be controversial to the class as a whole may be extremely controversial or difficult for one or two students.

Finally, one or two students may have extreme or idiosyncratic views and be particularly unwilling to engage respectfully with other views. A few polarizing students can co-opt a discussion or even a course.

Even knowing that a course will confront politicized issues, easily personalized issues or even that your class contains polarizing or marginalized students, sometimes the most controversial subject is one that sneaks up on you. For example, the most controversial topic in a 
gender seminar might not be abortion, but instead the validity of some women's decision to be at-home-mothers, topics surrounding equity in education as protected by Title IX, or even the treatment of women in the military. Classes concerning rape law may disintegrate into a gendered war over consent when a woman is intoxicated (instead of a debate over the statutory interpretation of rape laws or the policy behind them). Exploration of child support laws may devolve into debates over men's obligation to support children they did not want. Some but not all controversy can be anticipated: after all, each class — each student — may react differently to the same material.

The most daunting pedagogical task arises when a topic touches all three of the categories set forth: the topic that is simultaneously politicized, personalized and draws out marginalized or radicalized students. In this context - and when more manageable controversy arisesprofessors and their classes fare better if the professor started laying the groundwork to address controversy long before it arises.

\section{Laying the Groundwork}

Family law, with its dynamic and ever-changing nature in the law and in society, is fertile ground for any related topic to (d)evolve into classroom controversy. This is not to say controversy is bad - to the contrary, it may prove productive - but productivity requires planning.

Because of this variety of ways in which controversial topics can arise, it is useful to plan for difficult discussions throughout a course, rather than trying to re-tool for one or two class sessions that you expect to be flashpoints. Discussions of difficult topics will go more smoothly 
if the professor and students have established an environment of trust and mutual respect over the course of the semester. You can start to create such an environment even before the course begins.

\section{$\underline{\text { Course marketing }}$}

A course description is both an opportunity to recruit students and to start setting their expectations regarding course content. If your concern is that certain perspective might be missing from the class, your course description can emphasize the broad range of topics that will be covered, casting a wide net over possible topics of interest to students. For example, many students assume that a course on Family Law is a course on the law of the nuclear family. They may not realize that the question "What is a family?" is a major topic in many courses. If yours is one of them, it's easy to make that clear in the course description. If you think that your Women and the Law course might benefit from having more students who are male and/or conservative, the course description can emphasize the broad range of topics that will be covered-marketing the course as a mini-course on employment law, property, criminal law, gender in the military in addition to gender, sexuality and family law, for example, may draw students to the class in which they might otherwise not be interested. Simply specifying that a class looks at discrimination against men and women, or the evolving definition of "family" may entice groups who would ordinarily be less likely to join the class.

On the other hand, it may be appropriate to market the class more narrowly. Especially in an upper-level class, it may be fine to design a class for students who share a general perspective on the topic. For example, you might teach a seminar on reproductive rights that takes the need for and importance of reproductive rights as a starting point rather than a matter up for debate. It 
is difficult to delve into more advanced theoretical discussions if the class cannot get beyond a debate over first principles, so it is pedagogically appropriate to take some debates off the table for purposes of your class, assuming that this decision is clearly indicated in the course description so that students to self-select out of the conversation. This approach may not be acceptable at some institutions, however, particularly those that have few course offerings related to controversial topics.

\section{From day one}

Heavy-handed classroom management, through understandably tempting when faced with teaching controversial topics, can backfire. Specifically, dictatorial control of the classroom —or even of singular, challenging students — may dampen discussion down to a whisper. Therefore, teaching controversial topics requires professors to set clear expectations regarding classroom behavior and discussion decorum without striking so much fear into students that they become reluctant to participate at all.

On the first day of class you can discuss ground rules for discussion, highlighting that the class will cover some controversial ground. Make clear that rude or inappropriate comments will not be allowed, and plan in advance for how to handle them when they occur. Some professors may want to dictate that such comments will lead to immediate expulsion from class. It may also be effective to start the class by saying it is a given that each student and the professor will say something at some point in the semester that others may find offensive and inviting students to resist personalizing the comment, instead using it as an opportunity to have a productive dialogue. Doing so acknowledges that controversial topics tend to provoke strong responses and 
provides some assurance that the students are seen as whole persons, not just as the speaker of individual comments.

An important aspect classroom management is deciding how to handle "outliers." An outlier is a student with extreme or ill-informed opinions, extreme ways of expressing those opinions, or simply a student who tries to dominate class discussion. These students are not necessarily inappropriate, but one outlier student can shift the tone of an entire class for an entire semester. The immediate temptation is to curtly shut an outlier student down, but doing so can have grave consequences. Shutting down outlier students in class may actually engender empathy toward the outlier from the other students and negatively alter the tone of the class. The professor's actions can be interpreted as biased against a viewpoint instead of an exercise in classroom control, thereby chilling further class participation. Instead of addressing the issue in class, it may be prudent to discuss the outlier student's behavior with that student privately outside of class. Announcing this policy at the beginning of the course may also allay student fears that they will be chastised publically_which is a common fear in classes the address controversial subjects - thereby having the effect of decreasing student trepidation and increasing class participation.

Not all the ground rules need be dictated by the professor. Another approach is to allow the class to discuss how to handle specific situations, such as when a student (or the professor) shares a personal experience related to the topic being studied. Care must be taken, however, to always make it clear that the professor will protect students from unwarranted comments on their personal experiences or opinions to the extent possible. As classroom discussions often continue after class, consider including dialogue and mediation skills among your explicit teaching 
objectives. To be able to engage in respectful dialogue over an issue of profound disagreement and to deal sensitively with emotionally difficult subjects are important lawyering skills.

\section{$\underline{\text { Patterns equal predictability }}$}

In addition to explicit ground rules, in the first few weeks of a course you set a pattern for class discussions. For example, many law school courses emphasize the importance of seeing both sides of an argument. Often, they do this by encouraging students to tear down or poke holes in any argument that is presented. If you set this pattern, remember that students will likely follow it for controversial topics as well. If you introduce a topic by trying to build up empathy for one side of the issue, the students will respond by attacking it, leading you to a confrontation you may have been trying to avoid. A more productive technique in a typical law classroom may be to use structured controversy, where a pair or group of students are assigned opposing roles to play and the subsequent confrontation is controlled by the professor, who poses specific topics to be addressed by each viewpoint. Structured controversy may have the added benefit of depersonalizing controversial topics.

For a class that will not follow a typical law school model, it is helpful to establish early on that it is a different kind of class. In a Feminist Jurisprudence class, for example, the class might start with a discussion of the question, "When did you first notice the world is gendered?" Each student has the chance to tell her or his own "coming of age" story, and no comments or responses are allowed. This opening tells students that their own experiences and perspectives will be an important and valued aspect of the class and sets a tone of listening and respect rather than confrontation. 
Regardless of the approach employed, using consistent methods for tackling controversial topics provides and air of predictability for students and control for professors.

\section{Approaching Controversial Topics}

When it comes to presenting a topic that you expect (or have just discovered) to be controversial, you will want to present all sides of the argument. There are several approaches to doing so. Many professors begin with an opening lecture giving primacy to the side that they do not align with, although this can backfire if the view is a small minority in the class. There are many techniques, however, for presenting the controversial topic in its entirety and in context.

This section collects ideas for specific classroom strategies and resources when you expect a topic to be controversial. The suggestions fall into three broad categories:

Who stands for what: techniques for deciding who in the classroom advocates for which position.

Media and pop culture: resources for bringing in views that may be marginalized in the classroom, or for reducing tension through humor.

Shifting ground: blunting controversy by confronting it obliquely, using lenses other than "which view is right and which is wrong."

\section{Who stands for what}


When preparing to teach a controversial topic, give some thought to who "represents" particular views in the classroom, and when it would be better to put some distance between individuals and arguments.

When a subject is uncomfortably personal for the professor, it may be helpful to let an outsider - a colleague or a guest speaker - teach a class. An outsider can be especially helpful if a professor feels strongly about an issue and most of the class disagrees with that viewpoint. When a particular viewpoint is presented by an outsider, the professor is not responsible for that view. In later discussions, the speaker can "stand in" for that view so that the professor does not end up arguing against the class. Non-lawyer guest speakers can serve this role as well. For example, inviting activists or parties to same-sex marriage litigation to talk about their experiences can shift the "personal" part of the discussion away from students. Alternatively, inviting an outside speaker to represent a view to which the professor is strongly opposed provides an opportunity to model respect for opposing viewpoints and assure all students that their views are taken seriously.

Using the expertise of colleagues may also prove helpful. Reproductive rights, for example, are discussed in Family Law, Constitutional Law, and Law and Gender, in addition to other, more specialized courses. Colleagues teaching those subjects are potential guest speakers who already have prepared a class on the topic. Ideally, they also represent an opportunity to coordinate teaching so that students are exposed to a broad range of approaches over more than one class.

It can also be helpful to take the temperature of the class on controversial topics. If this is done at the very beginning of a course, it can provide valuable information on who stands for 
what in the classroom, generally speaking of course. Blind surveys are quick and easy using classroom clickers or TWEN. In addition Internet resources, such as surveymonkey.com allow professors to create surveys for students to take confidentially on their own time. Significantly, a survey can alert you when there is a group in the class that is likely to be marginalized. You can use the survey results only for your own information, or you can share them with students. Sometimes knowing where they stand in the class can help students avoid feeling blindsided by the discussion that ensues. In addition to providing the professor with useful background on the class, the voluntary survey on controversial topics may show surprisingly diverse opinions. Sharing the survey results may encourage those with minority viewpoints to share their thoughts,comforted with the knowledge that they were not alone, and lead the class to listen more carefully to minority opinions. It is important, however, to tell students upfront whether the survey is in fact blind and to inform them how the survey will be used.

Regardless of where the class as a whole stands on a particular issue, often there are a few students who are especially vocal on certain issues. While it can be nice to have a reliable source of comments that will move the class along, it is usually counter-productive to allow one student to become the "poster child" for any particular view.

When one side of a debate is absent, under-represented, or even vilified by the class a whole, a moot court exercise — with assigned sides — can help flesh out the arguments. Assigning a student to make the argument for the disfavored side allows it to be presented safely, from the student's perspective, since everyone knows it is an exercise. This works best if the students take it seriously, with no laughing at or apologizing for the argument. Use this exercise with caution, however, when students' views reflect heartfelt moral commitments. Legal education can be 
profoundly alienating for students who feel that the law is in tension with their deeply held beliefs, and the view that a lawyer ought to be able to "make the argument" for any possible result contributes to that alienation. While students should be expected to understand opposing arguments, professors should strongly consider whether students should be required to perform them as part of an in-class exercise.

\section{Media and pop culture}

Pop culture can help introduce a topic by giving students a shared and well-known case study. Celebrity examples can provide springboards for discussing issues such as marriage and divorce (Jon and Kate Gosselin), assisted reproduction (Nadya Suleman), rape (the Kobe Bryan case), incest (Woody Allen), domestic violence (Rhianna), and pornography (Pamela Anderson). During class, you can talk about these examples or use music or video clips to highlight certain points. Novels or full-length movies viewed outside of class can also help open up discussion on controversial topics. YouTube.com is an excellent resource for short media clips. One of the strengths of fiction is that it can flip assumptions on their head and carry ideas to extremes, creating fertile areas for discussion. For highly emotional topics or films, students may select their own small groups to watch and discuss a particular movie, avoiding open class discussion and giving students time to recover from their personal reactions. Care should always be taken, however, to thoroughly view, listen to or read media clips prior to using them in class. Lyrics and video can be unexpectedly explicit when closely scrutinized.

One pitfall to watch out for is that the celebrity examples may be unrealistic and may trigger pre-existing judgments that students have formed without much analysis. For example, the portrayal of street prostitution in the movie Pretty Woman is highly unrealistic and 
glamorized. To offset those tendencies, try juxtaposing celebrity examples with documentaries. Another potential pitfall of movies is that they can overwhelm the students. For example, films about domestic violence can be very power emotionally. To build in some distance, you can allow students to watch films outside of class, with self-selected small groups, so that they have a chance to discuss the experience informally.

While we may think of pop culture references as a way to keep our teaching current, cultural references can also teach history. For example, popular love songs can show how ideas about love, romance, and marriage have changed over time. Op-eds and New Yorker cartoons can also provide snapshots of an era.

News media outlets are also a valuable source of information and discussion points on controversial topics. Op-eds are especially useful for keeping a class from polarizing when they demonstrate the diversity and complexity of people's political views, such as editorials by Republicans for abortion rights or Democrats against them. Structuring the class in such a way that rewards students who identify current, newsworthy events linked to class is also beneficial. Moreover, giving students some form of credit for relevant newsgathering encourages students to identify coverage with varied points of view. Discussing the coverage of a controversial topic can be used as a proxy for discussing the varied viewpoints within the controversy itself and has the valuable side effect of depersonalizing the resultant discussion.

\section{$\underline{\text { Shifting ground }}$}


A final strategy for defusing controversy is also a valuable exercise in its own right: explicitly shifting your analytical framework away from rights and wrongs, in favor of a different approach to analysis. For example, reproductive "rights" may be shifted to focus instead on the rhetoric surrounding issues such as birth control, abortion, and cesarean birth. The class can analyze whether rhetorical devices add to or distract from judicial decisions. The controversy is still present, but less so than in a "rights" framework. The result can be a robust discussion that covered the views on these controversial issues focused more on the structure of the legal arguments involved.

There are additional ways to make the arguments rather than rights the subject of discussion. Law students can be asked to focus on procedural and methodological aspects legal problems and decisions. For example, cases such as Roe v. Wade and Bowers v. Hardwick ${ }^{5}-$ and their later treatment in Planned Parenthood v. Casey $^{6}$ and Lawrence v. Texas ${ }^{7}$-can be discussed in terms of the role precedent plays or should play in Supreme Court doctrine.

Another strategy is to ask the class to experiment with taking arguments to their extremes. Playing out the consequences of any single argument, taken as an absolute, helps reveal the assumptions that underlie the argument and expose possible faults. For example, in discussing abortion, students sometimes make categorical assertions - derived from political talking points - about a woman's right to control her body or when life begins. At the same time, many of the scholarly arguments about, for example, the relationship between abortion and sex equality, tend to strike students as bizarre. Methodically exploring the implications of both kinds

\footnotetext{
${ }^{4} 410$ U.S. 113 (1973).

${ }^{5} 478$ U.S. 186 (1986).

${ }^{6} 505$ U.S. 833 (1992).

${ }^{7} 539$ U.S. 558 (2003).
} 
of arguments helps students slow down their judgment and develop a more complex understanding of the subject. Another way to shift ground is to ask the class to discuss whether groups that benefit from gender-based discrimination should be willing to give up that benefit to promote equity. It is especially useful to flip this argument. For example, one might start a discussion on the gendered aspects of Family Law by asking whether women, who are often seen as suffering most from gender-based discrimination, should be willing to give up their advantage in custody proceedings in an effort to promote equity.

With all of these strategies, it remains important to apply your approach to both sides of an argument, or else your critique of rhetoric or playing out of consequences can come across as ridiculing of one side of the debate.

\section{Conclusion}

Teaching controversial topics can be the most rewarding aspect of teaching the law. Each class and each student present different challenges. Professors should not be surprised when techniques that were effective in one class are ineffective in the next. Teaching controversial topics requires a toolbox of techniques and a willingness to engage in honest selfreflection and pedagogical re-examination.

By exploring issues that provoke strong emotional reactions we help students see the moral and political foundations of our law in addition to strict legal constructs. But with this reward comes responsibility: responsibility to use controversial topics as a mechanism to explore the law, not to promote personal agendas; responsibility to present all sides of a controversy; 
and, most importantly, a responsibility to our students to maintain an environment conducive to learning. 